\title{
Risk of over-diagnosis of COPD in asymptomatic elderly never-smokers
}

\author{
J.A. Hardie*, A.S. Buist", W.M. Vollmer ${ }^{\ddagger}$, I. Ellingsen ${ }^{+}$, P.S. Bakke ${ }^{+}$, O. Mørkve ${ }^{+}$
}

Risk of over-diagnosis of chronic obstructive pulmonary disease in asymptomatic elderly never-smokers. J.A. Hardie, A.S. Buist, W.M. Vollmer, I. Ellingsen, P.S. Bakke, O. Mørkve. (C) ERS Journals Ltd 2002.

ABSTRACT: The Global Initiative for Chronic Obstructive Lung Disease (GOLD) has defined stage 1 chronic obstructive pulmonary disease (COPD) as forced expiratory volume in one second/forced vital capacity (FEV $1 / \mathrm{FVC}) \%<70 \%$ and a $\mathbf{F E V} 1 \%$ predicted of $>80 \%$. Stage 2 has been defined as FEV $1 / \mathrm{FVC}<70 \%$ and a FEV1\% pred of $<\mathbf{8 0} \%$. The authors examined the extent of COPD misdiagnosis using this definition in healthy, never-smoker, asymptomatic adults aged $>70$ yrs in Bergen, Norway. A respiratory questionnaire was mailed to a random sample of 2,871 persons aged $>70$ yrs. In a random, well-defined subgroup of 208 never-smoker respondents with no current respiratory disease and significant dyspnoea or heart disease/hypertension complicated with dyspnoea, 71 were able to perform an acceptable spirometry. Approximately $35 \%$ of these healthy, elderly never-smokers had an FEV1/FVC $\%$ of $<70 \%$ and would be classified as having at least a stage 1 COPD. This percentage increased with age and in those aged $>80$ yrs $\sim 50 \%$ would be classified as having COPD and approximately one-third would have an FEV1 of $<80 \%$ pred (stage 2 COPD). The estimated 5th percentile of FEV1 was consistently $<80 \%$ pred.

The Global Initiative for Chronic Obstructive Lung Disease criteria will probably lead to a significant degree of over-diagnosis of chronic obstructive pulmonary disease in those aged $>70 \mathrm{yrs}$. The criteria used to define the various stages of chronic obstructive pulmonary disease need to be age-specific.

Eur Respir J 2002; 20: 1117-1122.
*Institute of Internal Medicine, Deaconess Hospital, University of Bergen and ${ }^{+}$Dept of Thoracic Medicine, Haukeland Hospital, Bergen, Norway, "Division of Pulmonary and Critical Care Medicine, Oregon Health Science University and "Kaiser Permanente Center for Health Research, Portland, OR, USA.

Correspondence: J.A. Hardie, Institute of Internal Medicine, Deaconess Hospital, University of Bergen, Ulriksdal 8, N5009 Bergen, Norway.

Fax: 4755979435

E-mail: jon.hardie@med.uib.no

Keywords: Aged, chronic obstructive pulmonary disease, spirometry

Received: March 252002

Accepted after revision: June 162002

This study was supported by the University of Bergen (Bergen, Norway), Nasjonalforeningen for folkehelse (Oslo, Norway) and GlaxoSmithKline (Oslo, Norway).
The Global Initiative for Chronic Obstructive Lung Disease (GOLD) Workshop Summary has defined stage 1 chronic obstructive pulmonary disease (COPD) as airflow limitation where forced expiratory volume in one second/forced vital capacity $(\mathrm{FEV} 1 / \mathrm{FVC}) \%$ is $<70 \%$ and $\mathrm{FEV}_{1} \%$ predicted is $>80 \%$. Stage $2 \mathrm{COPD}$ has been defined as a $\mathrm{FEV} 1 / \mathrm{FVC} \%$ of $<70 \%$ and an $\mathrm{FEV} 1 \%$ pred of $<80 \%$. These criteria are set regardless of age in an attempt to simplify the diagnosis [1].

The trade-off with simplicity, however, comes at the expense of misclassification. Since the FEV1/FVC ratio falls with age [2-5], the use of a fixed cut-off point for defining COPD becomes more inaccurate with increasing age. In addition, the age-related decline in FEV1 means that using $80 \%$ of pred FEV1 to distinguish between the GOLD levels of severity for COPD will also be more inaccurate with increasing age. As a result, the GOLD criteria may lead to a significant degree of over-diagnosis of both the presence and severity of COPD in the elderly portion of the population.

The purpose of this paper is to illustrate the degree of over-diagnosis of COPD that the GOLD criteria might lead to in a healthy, asymptomatic elderly population, aged 70-100 yrs living in Bergen, Norway. Reference values for spirometry in elderly Northern Europeans are also presented.

\section{Methods}

Participants included in this analysis were residents of Bergen, Norway, who were originally recruited as part of a study to develop prediction equations for blood gases in a healthy, elderly population. The sample was recruited in two phases. Initially, a postal survey of an age- and sex-stratified, random sample of 2,871 individuals, aged $\geqslant 70 \mathrm{yrs}$, living in Bergen was conducted. These individuals were identified using a central population registry that includes the name, address, and birth date of every citizen or resident of Norway. The survey consisted of a translated version of the American Thoracic Society-Division Of Lung Diseases' respiratory questionnaire (ATSDLD) [6]. A total of 1,649 individuals $(57 \%$ of the initial sample) responded to the survey.

Of the 1,649 phase 1 respondents, 1,037 individuals 
were excluded as they reported: either current- or exsmoker status; physician-diagnosed chronic or current acute respiratory disease; grade 4 dyspnoea (after $100 \mathrm{~m}$ on level); and grade 3 dyspnoea (ever having to stop due to breathlessness on the level) and having been treated for heart disease or hypertension within the last $10 \mathrm{yrs}$. Individuals who reported a history of heart disease or hypertension, but who did not report grade 3 or 4 dyspnoea, were not excluded. Among the remaining 612 "healthy" individuals, the authors took a random subsample of 208 persons, again stratifying by age and sex, and invited them to participate in a clinical examination that included spirometry and measurement of blood gases. A total 95 participants $(47 \%)$ attended the clinic visit, and of these, 71 were able to perform acceptable spirometry. Phase 2 nonresponders and the 24 persons who were unable to perform spirometry were older and more likely to be female than the 71 with acceptable spirometry. The major reasons reported for failure to perform spirometry were medical contraindications, cough during manoeuvre, not able to follow instructions sufficiently, and unspecified desire to be excused from the testing (usually after trying once). In the total group of 137 persons (from the 208 originally sampled) who ended up not performing spirometry, $34 \%$ reported problems walking (as compared to $10 \%$ in the final participant group) and $18 \%$ resided in nursing homes (compared to $3 \%$ in the final participant group). Dyspnoea grade 1 or 2 was reported as being equally frequent at $\sim 6 \%$ in both participants and nonresponders.

\section{Spirometry}

Spirometry was performed using a Vitalograph drywedge bellows spirometer (Vitalograph, Buckingham, UK). The spirometer was calibrated at the beginning of each day using a $1-\mathrm{L}$ syringe with repeated strokes up to $9 \mathrm{~L}$. The subjects were first instructed in and then given a demonstration of the proper technique. All measurements were performed and reported according to ATS recommendation and at body temperature and ambient pressure, and saturated with water vapour (BTPS) [7] with the subject in the sitting position. Noseclips were used. FVC and FEV1 were recorded using the best values for each from any of the acceptable measurements. FEV1/ $\mathrm{FVC} \%$ was calculated by: $(\mathrm{FEV} 1 / \mathrm{FVC} \times 100)$. Height and weight were measured wearing indoor clothing without shoes.

\section{Statistical analysis}

Prediction equations for FEV1, FVC, and FEV1/ $\mathrm{FVC} \%$ were based on multiple linear regression analysis with age and height as predictor variables. The analysis was performed separately for each sex. Coefficients with corresponding SE, along with adjusted $\mathrm{R}^{2}$ and the residual $\mathrm{SD}$ for the model are reported. The lower limit of normal was estimated as:

$$
\begin{gathered}
\text { Predicted }-1.65 \times \text { residual } \mathrm{SD} \\
\text { (i.e. the estimated } 5 \text { th percentile) }
\end{gathered}
$$

\section{Results}

Sample characteristics are presented in table 1 . The age of participants ranged from 70-96 yrs, and 14\% of both males and females were aged $\geqslant 85$ yrs. Mean body mass index was $25 \mathrm{~kg} \cdot \mathrm{m}^{-2}$ for males and $28 \mathrm{~kg} \cdot \mathrm{m}^{-2}$ for females. The mean FEV $1 / \mathrm{FVC}$ ratios were $71 \%$ for males and $72 \%$ for females, while mean FEV1 for males and females was 2.72 and $1.71 \mathrm{~L}$, respectively. Of the subjects in the final sample, four had reported grade 1 dyspnoea and none had reported grade 2 dyspnoea.

Sex-specific prediction equations for FEV1, FVC, and their ratios are presented in table 2. None of the regression coefficients differed significantly between males and females.

Although FEV1/FVC\% showed a significant inverse relationship to age (fig. 1), its overall distribution was approximately normal in shape (fig. 2). The GOLD threshold for defining COPD, a FEV1/FVC ratio of $70 \%$, was only $0.25 \mathrm{sD}$ below the mean for this healthy, never-smoking cohort. As shown in table 3, $\sim 35 \%$ of the healthy elderly subjects in this reference sample would be diagnosed as having at least mild COPD by the GOLD criteria. This percentage increases by age and in the $\geqslant 80$ yrs age group, $\sim 50 \%$ would have a COPD diagnosis and approximately one-third of these would have moderate COPD (table 3 and fig. 1).

Figure 3 shows (as an example for males $170 \mathrm{~cm}$ and females $160 \mathrm{~cm}$ ) predicted FEV1 by age along with the estimated lower 5th percentile ("lower limit of normal") and the calculated $80 \%$ pred FEV1. The lower 5th percentile was consistently $<80 \%$ of pred FEV1. Of course, the difference between the 5th percentile and $80 \%$ of pred increases by age, as the

Table 1.-Age- and sex-distribution of the sample with mean anthropometric and spirometric data

\begin{tabular}{lcc}
\hline & Male & Female \\
\hline $\begin{array}{l}\text { Subjects n } \\
\text { Age distribution yrs \% (n) }\end{array}$ & 40 & 31 \\
$\quad 70-74$ & $27(11)$ & $35(11)$ \\
$75-79$ & $30(12)$ & $29(9)$ \\
$80-84$ & $30(12)$ & $19(6)$ \\
$85-89$ & $8(3)$ & $10(3)$ \\
$\geqslant 90$ & $5(2)$ & $7(2)$ \\
Weight kg & $74 \pm 10$ & $69 \pm 14$ \\
Height cm & $173 \pm 7$ & $158 \pm 8$ \\
Body mass index $\mathrm{kg} \cdot \mathrm{m}^{-2}$ & $25 \pm 3$ & $28 \pm 5$ \\
FVC L & $3.80 \pm 0.79$ & $2.36 \pm 0.69$ \\
FEV1 L & $2.72 \pm 0.66$ & $1.71 \pm 0.54$ \\
FEV1/FVC $\%$ & $71.3 \pm 6.0$ & $72.1 \pm 6.9$ \\
\hline
\end{tabular}

Data are presented as \% (n) or mean \pm SD. FVC: forced vital capacity; FEV1: forced expiratory volume in one second. 
Table 2. - Prediction equations for the forced expiratory volume in one second (FEV1), forced vital capacity (FVC), and $\mathrm{FEV}_{1} / \mathrm{FVC} \%$ of healthy never-smokers in the present study

\begin{tabular}{lcccccc}
\hline & Constant & Age yrs & Height $(\mathrm{cm})$ & Estimated LLN $^{\#}$ & R $^{2}$ & Residual SD \\
\hline FEV1 L & & & & & \\
$\quad$ Male & -0.865 & $-0.044(-0.076-0.0013)$ & $0.041(0.014-0.069)$ & -0.91 & 0.30 & 0.55 \\
$\quad$ Female & 0.333 & $-0.041(-0.067--0.015)$ & $0.029(0.008-0.051)$ & -0.59 & 0.57 & 0.36 \\
FVC L & & & & -1.07 & 0.32 & 0.65 \\
$\quad$ Male & -2.75 & $-0.044(-0.082--0.006)$ & $0.058(0.026-0.091)$ & -0.78 & 0.54 & 0.47 \\
$\quad$ Female & -1.34 & $-0.041(-0.075-0.007)$ & $0.044(0.016-0.072)$ & -9.57 & 0.06 & 5.8 \\
FEV1/FVC $\%$ & & & & -10.73 & 0.13 & 6.5 \\
$\quad$ Male & 95.2 & $-0.30(-0.64-0.04)$ & & & \\
$\quad$ Female & 107.4 & $-0.44(-0.83-0.06)$ & & & \\
\hline
\end{tabular}

The $95 \%$ confidence intervals for the individual coefficients are in parenthesis. ${ }^{\#}$ : given value is $1.65 \times$ residual SD. Calculation of the estimated lower limit of normal (LLN) for an individual will then be: predicted-1.65 $\times$ residual SD.

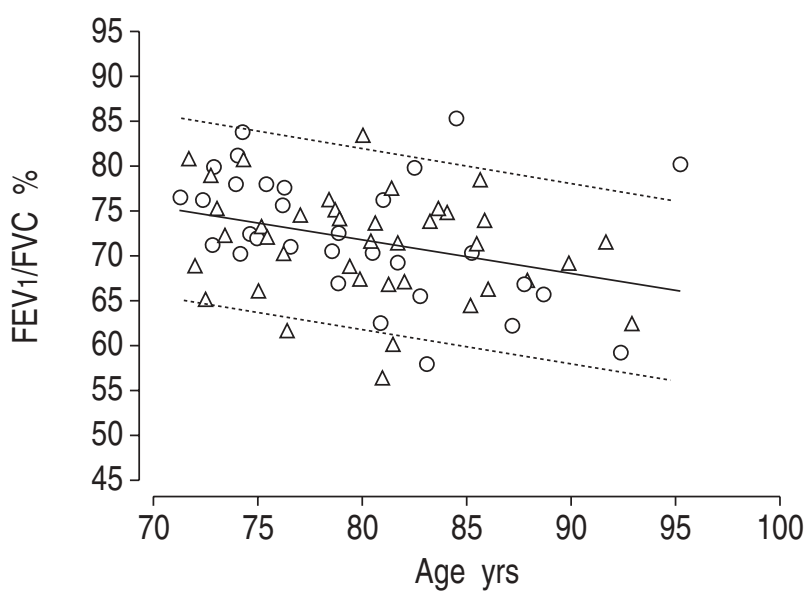

Fig. 1.-Forced expiratory volume in one second/forced vital capacity $(\mathrm{FEV} 1 / \mathrm{FVC}) \%$ by age in the healthy reference sample of the present study. Lines represent regression of $\mathrm{FEV} 1 / \mathrm{FVC} \%$ by age $(-)$ with 5 th and 95 th percentiles $(\cdots \cdots \cdots \cdots) . \triangle$ : females; : males.

$80 \%$ of pred is a relative measure whereas the lower limit of normal remains an absolute distance from the predicted value.

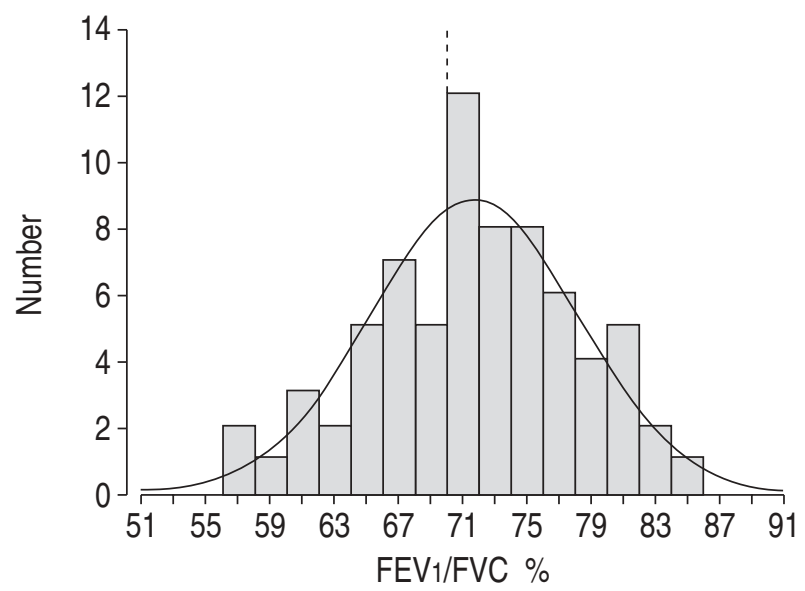

Fig. 2.-Distribution of forced expiratory volume in one second/ forced vital capacity $(\mathrm{FEV} 1 / \mathrm{FVC}) \%$ in the healthy reference sample of the present study. Dashed line represents $70 \%$. Mean \pm SD: $71.6 \pm 6.39$. $n=71$.

\section{Discussion}

This study clearly demonstrates that the recently published GOLD guidelines for diagnosis and treatment of COPD falsely classifies a substantial number of healthy, never-smoking older adults as having COPD, and that this phenomenon is more pronounced with increasing age. One-half of the 34 males and females aged $>80$ yrs would have been classified as having COPD, and of these, approximately one-third would have been classified as having moderate-to-severe COPD, even though all were never-smokers and none reported either respiratory symptoms or a prior physician diagnosis of pulmonary disease.

There is a clear limitation to this study in that these are spirometry values prior to any attempt at bronchodilation with a $\beta$-agonist. GOLD defines COPD based on postbronchodilator spirometry tests, a choice consistent with the concept of COPD being a disease characterised by (mostly) irreversible airway obstruction. It is likely that some of the subjects in the present study with low FEV1 would have an increase in $\mathrm{FEV} 1$ and rise above $70 \%$ for $\mathrm{FEV} 1 / \mathrm{FVC} \%$ and/or $80 \%$ pred FEV1 after inhaling a $\beta$-agonist. LEHMANN and GULSVIK [8] recently conducted a study

Table 3.-Per cent of healthy elderly subjects in the reference sample with chronic obstructive pulmonary disease (COPD) as defined by Global Initiative for Chronic Obstructive Lung Disease (GOLD) workshop summary

\begin{tabular}{lccc}
\hline & \multicolumn{3}{c}{ Age yrs } \\
\cline { 2 - 4 } & $70-79$ & $>80$ & All \\
\hline Subjects n & 37 & 34 & 71 \\
No COPD: & $78 \%$ & $50 \%$ & $65 \%$ \\
$\quad$ FEV 1/FVC $\%>70$ & & & \\
Stage 1 COPD: & $19 \%$ & $32 \%$ & $25 \%$ \\
$\quad$ FEV1/FVC $\%<70 ;$ & & & \\
FEV1\% pred $>80$ & & & \\
Stage 2 COPD: & $3 \%$ & $18 \%$ & $10 \%$ \\
$\quad$ FEV1/FVC $\%<70 ;$ & & & \\
FEV1 $\%$ pred $<80$ & & & \\
\hline
\end{tabular}

FEV1: forced expiratory volume in one second; FVC: forced vital capacity; \% pred: \% predicted. 

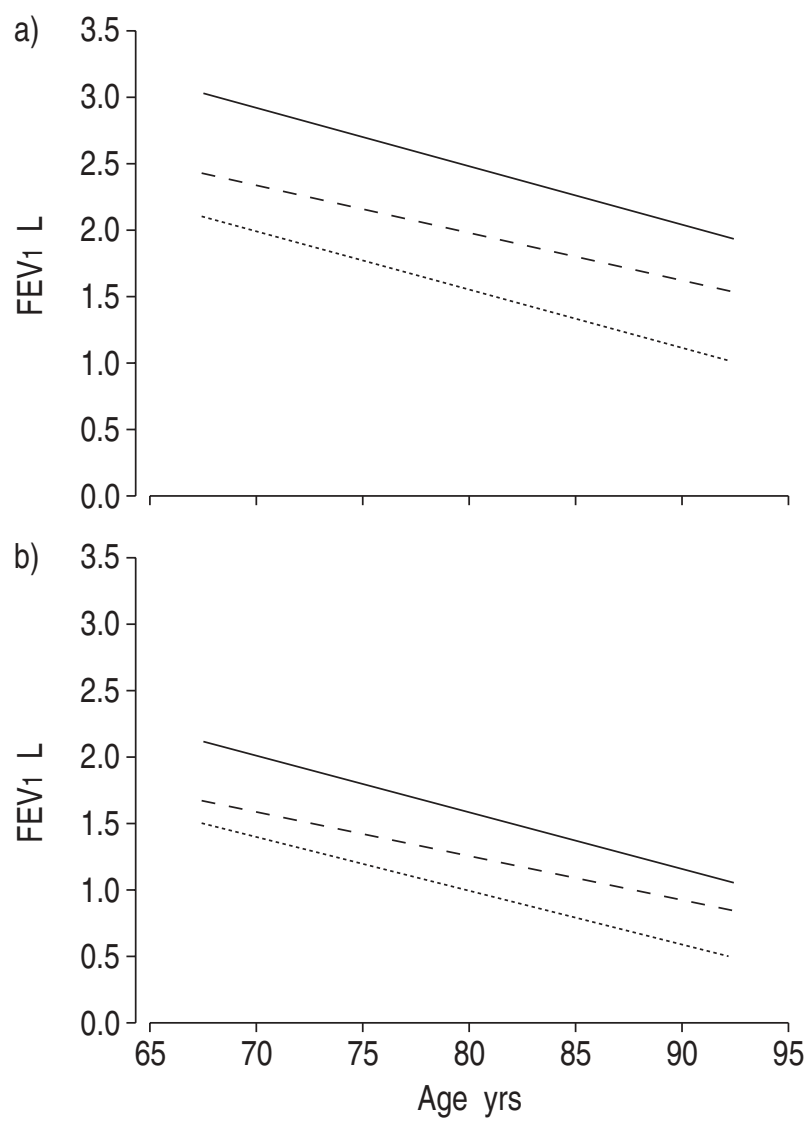

Fig. 3. - Forced expiratory volume in one second (FEV1) for a) males $170 \mathrm{~cm}$ in height and b) females $160 \mathrm{~cm}$ in height, with lower 5th percentile and calculated $80 \%$ of predicted FEV1. - : predicted; …....... lower limit of normal; ------: $80 \%$ pred.

of bronchodilator response in the general population of Bergen. In the age cohort 71-73 yrs, they found the prevalence of stage 1 obstruction $(\mathrm{FEV} 1 / \mathrm{FVC} \%<70)$ to be $18.2 \%$ before bronchodilation and $14.7 \%$ after bronchodilation, and prevalence of stage 2 obstruction to be $13.1 \%$ before and $10.4 \%$ after (calculated based on data presented). Since these figures were from a general population sample, a somewhat smaller effect in the asymptomatic subgroup might reasonably have been expected. However, it may still be reasonable to adjust down the estimates of overdiagnosis to account for bronchodilation. The adjusted frequency of stage 1 COPD would be $\sim 20 \%$ and stage 2 COPD would be $\sim 8 \%$.

The elderly persons in this study were selected at random from a subset of respondents to a postal questionnaire survey who reported no physiciandiagnosed chronic or acute pulmonary disease or significant symptoms thereof. Since well over one-half of the selected subjects either could not meet for testing or were unable to perform spirometry, it is possible that a nonresponse bias could have been present. However, there seems little reason to believe that these nonresponders would have better spirometric values than the present study subjects. The reasons for nonresponse are unknown but probably had to do with general frailty and inability to get out of the house or nursing home. In the sample, the frequency of walking disability, heart disease, and stroke was significantly higher among the nonresponders than among the study subjects (presently unpublished data). For these reasons, it is believed that individuals included in the analysis were of at least average lung health and sufficiently representative of the general, healthy lung, elderly population.

Although the number of subjects in the present data set are smaller than one might want, the results are consistent both with reference values reported from previous studies in the elderly [3, 4] and values reported from studies in younger age groups $[2,5,9$, 10]. This applies to both estimated age and height coefficients and measures of variation in the data, as shown in table 4. For example, the empirical lower 5th percentile of $\mathrm{FEV} 1 / \mathrm{FVC} \%$ in the Cardiovascular Health Study data set [3] was $\sim 11 \%$ points under the predicted and in the National Health and Nutrition Examination Survey (NHANES) III [4] data set, was $\sim 10 \%$ under the predicted. Although there are insufficient data points in the present study to determine the empirical 5th percentile, it is estimated that the 5th percentile $(1.65 \times$ residual $\mathrm{SD})$ is $\sim 10 \%$ points under predicted.

The age coefficients in the present study were generally larger (i.e. suggesting steeper rates of decline of lung function over time) than in previous studies $[2,3,10]$. This may have been the result of different

Table 4. - Comparison of predicted values for subjects aged $70 \mathrm{yrs}$, age regression coefficients, and variation around regression from previous reference value studies

\begin{tabular}{|c|c|c|c|c|c|c|c|c|c|c|c|c|c|}
\hline \multirow{2}{*}{\multicolumn{2}{|c|}{ First author [ref. no.] }} & \multicolumn{6}{|c|}{ FEV1 } & \multicolumn{6}{|c|}{$\mathrm{FEV} 1 / \mathrm{FVC} \%$} \\
\hline & & \multicolumn{3}{|c|}{ Male } & \multicolumn{3}{|c|}{ Female } & \multicolumn{3}{|c|}{ Male } & \multicolumn{3}{|c|}{ Female } \\
\hline & Subjects $n$ & Pred $^{\#}$ & Age & $\mathrm{RSD}^{-}$ & Pred $^{\#}$ & Age & $\mathrm{RSD}^{\top}$ & Pred $^{\#}$ & Age & $\mathrm{RSD}^{\top}$ & Pred $^{\#}$ & Age & $\mathrm{RSD}^{\top}$ \\
\hline Present study & 71 & 3.03 & -0.044 & 0.55 & 2.10 & -0.041 & 0.36 & 74.2 & -0.30 & 5.8 & 76.6 & -0.44 & 6.5 \\
\hline ENRIGHT [3] & 777 & 2.80 & -0.027 & 0.51 & 2.13 & -0.033 & 0.30 & 73.2 & -0.29 & 6.9 & 75.4 & -0.24 & 6.7 \\
\hline CRAPO [2] & 251 & 3.14 & -0.024 & 0.49 & 2.11 & -0.026 & 0.33 & 77.8 & -0.15 & 4.8 & 76.6 & -0.25 & 5.3 \\
\hline GULSVIK [9] & 470 & 3.17 & & & 2.20 & & & 83.3 & -0.09 & 4.3 & 80.7 & -0.10 & 4.6 \\
\hline QUANJER [5] & & 2.79 & -0.029 & 0.51 & 1.97 & -0.025 & 0.38 & 74.6 & -0.18 & 7.2 & 75.8 & -0.19 & 6.5 \\
\hline HANKINSON [4] & 7429 & 2.87 & & & 2.17 & & & 73.6 & -0.21 & & 75.9 & -0.21 & \\
\hline KNUDSON [10] & 112 & 2.75 & -0.029 & 0.52 & 2.16 & -0.040 & 0.38 & 79.3 & -0.11 & 6.3 & 78.8 & -0.19 & 7.6 \\
\hline
\end{tabular}

FEV1: forced expiratory volume in one second; FVC: forced vital capacity. ${ }^{*}$ : predicted (Pred) values for age 70 yrs, height $170 \mathrm{~cm}$ for males and $160 \mathrm{~cm}$ for females; ${ }^{\uparrow}$ : residual standard deviation (RSD) from the linear regression model containing intercept, height, and age. 
selection procedures in the sampling process. Both the studies by CRAPO et al. [2] and ENRIGHT et al. [3] were based on samples of recruited subjects where the effects of age may have been less apparent. The present study subjects came from a random sample of the general population. Another reason may have been that age-related decline of FEV1 accelerates in the elderly $[4,9,10]$. The present sample was started at age 70 yrs and thus, only looked at the steepest part of the age/FEV1 curve. The sample in the study by ENRIGHT et al. [3] was started at age $65 \mathrm{yrs}$, that by CRAPO et al. [2] at age $15 \mathrm{yrs}$, and KNUDSON et al. [10] at age $25 \mathrm{yrs}$ for males and 70 yrs for females. Thus the regression coefficients from these studies generally incorporated less steep parts of the curve. The variation around the regression (residual SD) in all of the named studies was very comparable to that of the present study; $\sim 0.50 \mathrm{~L}$ for FEV1 in males and $0.35 \mathrm{~L}$ for FEV1 in females. Consistent with the literature $[2-5,10]$, males exhibited greater residual variability around the regression lines for both FEV1 and FVC than females.

A significant number of subjects in this study had a FEV 1 of $<80 \%$ pred and/or an $\mathrm{FEV} 1 / \mathrm{FVC} \%<70 \%$. But this phenomenon is in no way new or unique to the present set of subjects. All of the previously mentioned reference value studies have shown similar findings in the elderly age groups. For example, based on reference values from the study by ENRIGHT et al. [3], an 80-yr-old male of $170 \mathrm{~cm}$ would have a lower limit of normal for FEV1, which is $66.8 \%$ pred.

More accurate, age-specific diagnostic limits for $\mathrm{FEV} 1 / \mathrm{FVC} \%$ would be $70 \%$ for individuals aged $<70 \mathrm{yrs}, 65 \%$ for those aged $70-80 \mathrm{yrs}$, and $60 \%$ for those aged $>80$ yrs. This adjustment for age, though still not as accurate as using 5th percentile values specific to each patient's age, sex and height, would minimise the degree of misclassification while still being relatively simple to apply. With regards to FEV1, making similar simplified guidelines is more difficult due to the strong dependency on both sex and height in addition to age. Making use of sex, age, and height-specific limits in the form of percentile curves or SD scores, for example, may be the only way to achieve sufficient accuracy. This, however, might be at the cost of simplicity.

Normal ageing of the lung can mimic the development of COPD in more ways than one [11]. The agerelated loss of elastic tissue in the lung parenchyma exposes the airways to dynamic collapse during expiration causing a "pseudo-obstruction" that may be undistinguishable from true obstruction when only looking at FEV1. In addition, with age, both the residual volume and the closing volume increase and alveolar walls disappear, producing a situation that has been termed "senile emphysema". The frequency of dyspnoea also increases with age in people not suspected of having lung disease [12,13]. All of these normal factors of ageing make determining limits for normality of lung function increasingly difficult. To date, spirometry has been the gold standard of choice for the diagnosis of obstructive pulmonary disease. It may not necessarily be the best choice for the elderly population.
It usually takes longer for elderly people to reach the "end-of-test criteria" of a plateau in the volume/ time curve $\left(<30 \mathrm{~mL} \cdot \mathrm{s}^{-1}\right.$ of flow $)$. There is likely to be less emphasis on achieving end-of-test criteria in clinical practice, particularly in elderly and frail individuals. Failure to empty completely will falsely raise the FEV1/FVC ratio and reduce the misclassification. Thus, the present estimates might overestimate the actual rate of misclassification in the clinical setting.

Comorbidity is common in the elderly. The selection and exclusion criteria used in this study were designed with the hope that the sample would specifically and realistically portray the healthy lung, elderly population. This meant that exclusion criteria were kept to a minimum to avoid an exaggerated healthy selection bias. For example, persons who reported having been treated for hypertension in the last $10 \mathrm{yrs}$ were only excluded if they also reported dyspnoea grade 3 . Hypertension has previously been associated with lower values of FEV1 [14] such that including these persons may affect the findings. It could still be argued that unless it is decided that hypertension-related low FEV1 should be called a form of COPD, hypertension in itself should not be used as an exclusion criterion.

The economic cost that this form of misdiagnosed COPD would incur in the community is difficult to measure. The actual degree of over-diagnosis in the general population will probably be fairly small, as individuals without symptoms will not be tested. Of those that, for some reason, get tested, most would have asymptomatic stage 1 COPD and, according to the GOLD guidelines, might be offered bronchodilators for use as needed. Their use would probably be minimal since the subjects would be asymptomatic to begin with. Subjects classified as having stage 2 COPD might be prescribed one or two regular bronchodilators and possibly also regular inhaled glucocorticosteroids. Potentially, up to $10 \%$ of the healthy elderly population might receive this misdiagnosis of stage 2 COPD and be at risk of being put on regular treatment. The actual cost of this is still difficult to estimate, as the compliance to treatment might be expected to be poor in this asymptomatic group.

A scenario in which individuals with transient respiratory symptoms or respiratory symptoms caused by other organ disease may be incorrectly diagnosed as obstructive is more likely to occur than a general over-diagnosis in the symptom-free population. For example, an 82-yr-old female with congestive heart failure, a $\mathrm{FEV} 1 / \mathrm{FVC} \%$ of $60-65 \%$ and $\mathrm{FEV} 1 \%$ pred of $75 \%$ would probably be labelled "obstructive" and be given bronchodilator treatment. Other direct and indirect economic costs of COPD diagnosis are probably not applicable to these individuals as they are less likely to require hospitalisation or other more intensive treatment regimens and have, in most cases, retired from the work force. The psychological cost to each of the misdiagnosed persons, however, could be significant and is obviously undesirable.

Based on these results and results from previous studies, it seems clear that direct application of the Global Initiative for Chronic Obstructive Lung 
Disease criteria for diagnosis of chronic obstructive pulmonary disease in the elderly may lead to an overdiagnosis of chronic obstructive pulmonary disease in the elderly. Criteria used to determine the normal limits of forced expiratory volume in one second and forced expiratory volume in one second/forced vital capacity per cent need to be age-specific. Further studies need to examine the predictive value of spirometry in the diagnosis of chronic obstructive pulmonary disease in this age group by including current-smokers and exsmokers, with and without symptoms of chronic obstructive pulmonary disease.

\footnotetext{
Acknowledgements. The authors would like to thank E. Nordeide and R. Espelid for their excellent technical assistance. They would also like to thank L. Johansen for continuous
} support.

\section{References}

1. Pauwels RA, Buist AS, Calverley PM, Jenkins CR, Hurd SS. Global strategy for the diagnosis, management, and prevention of chronic obstructive pulmonary disease. NHLBI/WHO Global Initiative for Chronic Obstructive Lung Disease (GOLD) Workshop summary. Am J Respir Crit Care Med 2001; 163 : $1256-1276$

2. Crapo RO, Morris AH, Gardner RM. Reference spirometric values using techniques and equipment that meet ATS recommendations. Am Rev Respir Dis 1981; 123: 659-664.

3. Enright PL, Kronmal RA, Higgins M, Schenker M, Haponik EF. Spirometry reference values for women and men 65 to 85 years of age. Cardiovascular health study. Am Rev Respir Dis 1993; 147: 125-133.

4. Hankinson JL, Odencrantz JR, Fedan KB. Spirometric reference values from a sample of the general
U.S. population. Am J Respir Crit Care Med 1999; 159: 179-187.

5. Quanjer PH, Tammeling GJ, Cotes JE, Pedersen OF, Peslin R, Yernault JC. Lung volumes and forced ventilatory flows. Report Working Party Standardization of Lung Function Tests, European Community for Steel and Coal. Official Statement of the European Respiratory Society. Eur Respir J 1993; 6: Suppl. 16, 5s-40s.

6. Ferris BG. Epidemiology Standardization Project (American Thoracic Society). Am Rev Respir Dis 1978; 118: 1-120.

7. Standardization of Spirometry, 1994 Update. American Thoracic Society. Am J Respir Crit Care Med 1995; 152: 1107-1036.

8. Lehmann S, Gulsvik A. Airflow limitations in middleaged and elderly people before and after adrenergic bronchodilation (Abstract). Eur Respir J 2000; 16: Suppl. 31, 388s.

9. Gulsvik A, Tosteson T, Bakke P, Humerfelt S, Weiss ST, Speizer FE. Expiratory and inspiratory forced vital capacity and one-second forced volume in asymptomatic never-smokers in Norway. Clin Physiol 2001; 21: 648-660.

10. Knudson RJ, Lebowitz MD, Holberg CJ, Burrows B. Changes in the normal maximal expiratory flowvolume curve with growth and aging. Am Rev Respir Dis 1983; 127: 725-734.

11. Janssens JP, Pache JC, Nicod LP. Physiological changes in respiratory function associated with ageing. Eur Respir J 1999; 13: 197-205.

12. Gulsvik A. Prevalence of respiratory symptoms in the city of Oslo. Scand J Respir Dis 1979; 60: 275-285.

13. Langhammer A, Johnsen R, Holmen J, Gulsvik A, Bjermer L. Cigarette smoking gives more respiratory symptoms among women than among men. The Nord-Trondelag Health Study (HUNT). J Epidemiol Community Health 2000; 54: 917-922.

14. Enright PL, Kronmal RA, Smith VE, Gardin JM, Schenker MB, Manolio TA. Reduced vital capacity in elderly persons with hypertension, coronary heart disease, or left ventricular hypertrophy. The Cardiovascular Health Study. Chest 1995; 107: 28-35. 